\title{
ANALYSIS OF OUT-0F-PLANE STABILITY OF BOW-STRING ARCHES
}

Several arch bridge superstructures, designed by the authors of the paper, are presented and analysed. Spatial FEM models were utilised to analyse behaviour of each bridge. Verification of out-of-plane buckling of the arches is discussed in more detail. Comparison of using beam and shell finite elements for the mesh of main beam-arch load-carrying system is given. The variation of top bracing system and its influence on the stability of the arches is presented, as well. A minimum load amplifier to reach the elastic instability of arches is used to estimate the suitability of the bracings. Comparisons of the assessment using results produced by first and second order global analyses are presented. Application of a unique global and local imperfection as the initial geometric imperfection is proposed.

Keyword: Arch bridges, bow-string girder, buckling, out-of-plane stability of arches, initial imperfection, elastic critical buckling modes.

\section{Introduction}

The paper deals with global analysis of bowstring-arch bridges, especially with verification of out-of-plane buckling resistance of the arches. For this purpose, the spatial transformation FEM models of five arch bridge superstructures recently designed by the authors of the paper were utilised. The primary models were modified in the parametric study, focused on effectiveness of different ways of stiffening the arches against the out-of-plane buckling [1]. That parametric study has been extended in this paper by another bridge superstructure and by further FEM models using shell finite elements for the mesh of main girderarch load-carrying system. The comparison of origin beam models with the shell models is made by the minimum load amplifier to reach the elastic instability of arches. Finally, comparison of the assessment using results produced by first and second order global analyses is presented.

\section{Analysed bridge structures}

The first bridge passes railway line over the Nosicky Water Canal. The bridge will be situated at $\mathrm{km} 159.038$ of the railway line Bratislava - Zilina and was designed as a four-span twoline steel railway bridge with theoretical lengths of single spans $62.4 m+124.8 m+124.8 m+62.4 m$, Fig. 1 . All four superstructures of the bridge consist of two bow-string girders with the bottom orthotropic bridge deck and the upper longitudinal bracing. The main beam and the circular curved arches are designed from passable box-sections. The vertical hangers, designed from steel tubes filled with concrete, are hinged to the beams and arches. The more detailed description of the whole bridge can be found in [1 and 2]. In the next study, the superstructure with span of $62.4 \mathrm{~m}$ will be designated as bridge "A", while the superstructure with double span $(124.8 \mathrm{~m})$ will have designation as "E".

TOTAL LENGTH OF THE BRIDGE $=450.65 \mathrm{~m}$ (in bridge axis)

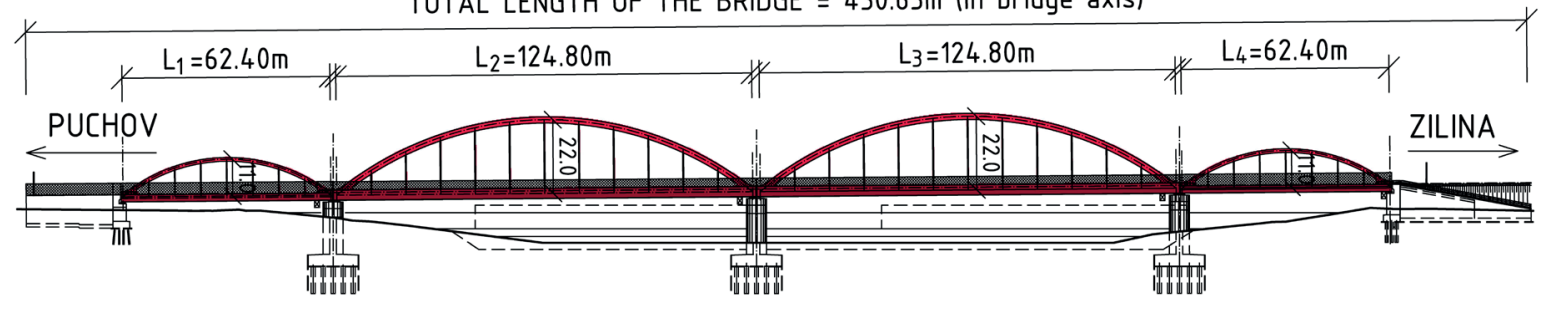

Fig. 1 Longitudinal view of the bridge over the Nosicky Water Canal

\footnotetext{
* Josef Vican, Jaroslav Odrobinak, Jozef Gocal

Department of Structures and Bridges, Faculty of Civil Engineering, University of Zilina, Slovakia

E-mail: josef.vican@fstav.uniza.sk
} 


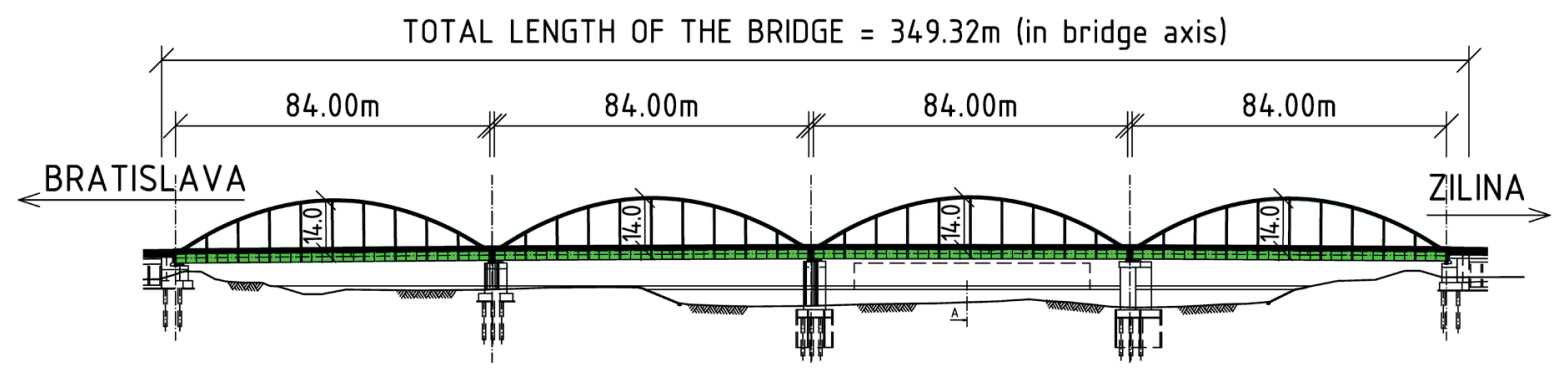

Fig. 2 Longitudinal view of the bridge over the Vah River in Trencin

The second bridge was designed over the Vah River in Trenčín City, just below the confluence of the Vah River and the Kockovsky Water Canal. The bridge is designed as a fourspan structure under each railway line with theoretical lengths of single spans of $84.0 \mathrm{~m}$, Fig. 2. The steel superstructures, marked as "B" in the next, consist of two bow-string girders with the bottom orthotropic bridge deck and the upper longitudinal bracing. The plate beams are designed from opened unsymmetrical I-shaped cross sections, while the parabolic curved arches are made of closed box-sections. The vertical hangers are designed from the symmetrical I-shaped cross-sections, fixed to the beams and arches in the plane perpendicularly to the plane of girders. The more detailed description can be found in [3].
The last railway bridge in the study was designed directly behind the railway station Liptovsky Hradok of the railway line Kosice - Zilina and it will cross the Bela River, a right-side inflow of the Vah River. The bridge is designed as two-line steel railway bridge with theoretical span length of $66.0 \mathrm{~m}$, Fig. 3 . The steel superstructure "C" consists again of the bow-string girders with the bottom orthotropic bridge deck and the upper longitudinal bracing. The plate beams as well as the circular curved arches are designed from passable box-sections. The vertical hangers positioned in the tenths of span are made of circular hollow sections. The more detailed description of the whole bridge can be found in [3].

Except four abovementioned superstructures of railway bridges, one road bridge superstructure (designated as "D") was included into the presented study. The road bridge on the

\section{TOTAL LENGTH OF THE BRIDGE $=79.26 \mathrm{~m}$}

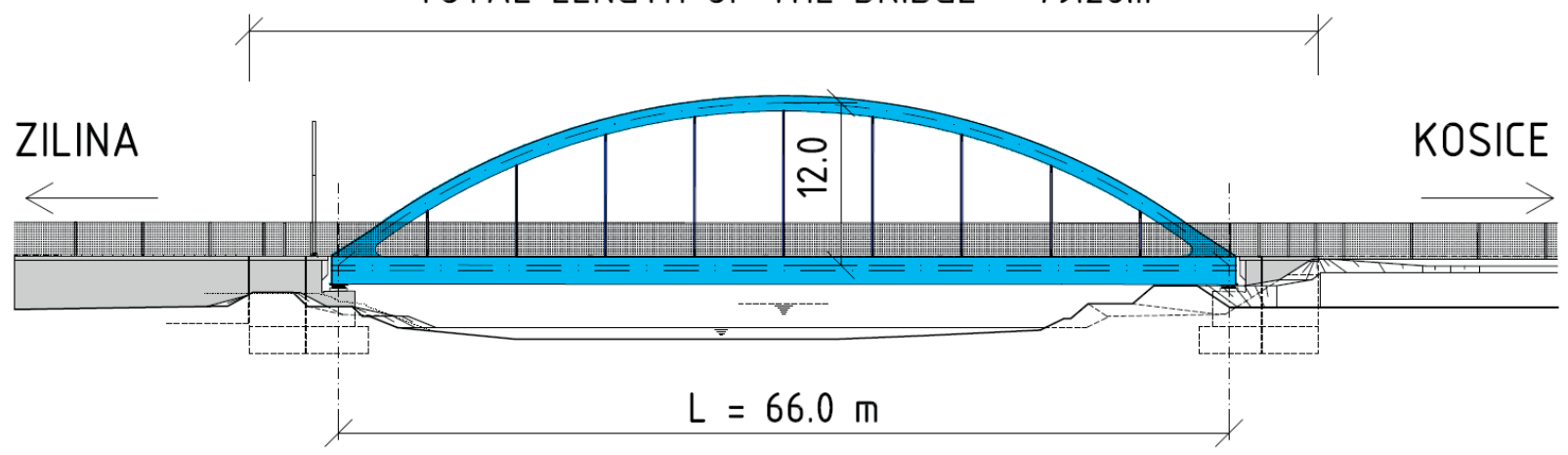

Fig. 3 Longitudinal view of the bridge over the Bela River

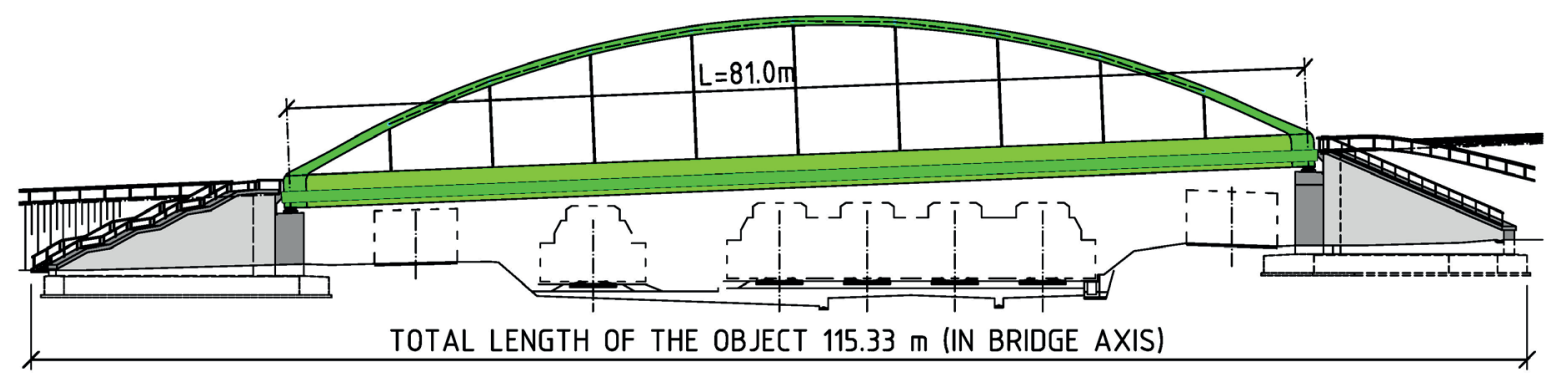

Fig. 4 Longitudinal view of the road bridge in Liptovsky Hradok City 
road I/18 in Liptovsky Hradok City spans two local roads and five railway tracks, Fig. 4 . The superstructure consists of two steel bow-string girders with theoretical span length of $81.0 \mathrm{~m}$ in axial distance of $12 \mathrm{~m}$, connected with the bottom steel and concrete composite bridge deck and the upper longitudinal bracing. The plate beams are designed as opened symmetrical I-shaped cross sections, except for the edge parts, where the single-web cross-section changes to double-web closed crosssection to connect better of the arch box-section. The vertical hangers are designed from steel rods hinged to the girders and arches.

\section{Study on stability analysis}

\subsection{Assumptions of the study}

The study, a part of which has been already published in [1], was primarily focused on influence of the upper longitudinal bracing on stability of the arches of two railway bridge superstructures from Fig. 1. Different types of the bracing system were incorporated into original computational models of the railway bridge superstructures. The first comparative model was considered without any top bracing system (I). Then, two basic types of top bracing systems were taken into account: the frame system (II) with varying number of cross-bars and the truss system (III) with various arrangements of diagonals, see Fig. 5. In all cases, the bracing members were designed as circular hollow sections. In case of truss bracing system the slenderness of members did not exceed the value of 150 . In this paper, the study has been extended by the additional three superstructures shown in Figs. 2, 3 and 4. Another extension of the study was achieved using further comparative FEM models with shell finite elements for the mesh of main girder-arch load-carrying system. Simplified designation of the bridges from A to $\mathrm{E}$ for the purpose of presented study is given in following Table 1 .

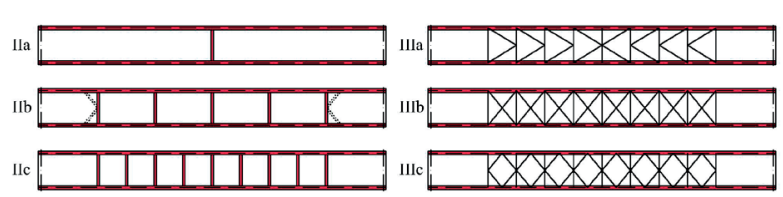

Fig. 5 Considered types of upper longitudinal bracings

\subsection{FEM modelling}

Utilisation of the commercial software based on Finite Elements Method (FEM) allows for spatial behaviour of bridges. Steel plates of the orthotropic deck of railway bridge superstructures were meshed by shell finite elements, as well as the reinforced concrete deck of the road bridge. Two basic concepts for modelling of the rest bridge geometry were adopted. In so called "member" models, the beam finite elements were used for modelling main girders, arches, hangers and top bracings. The longitudinal and transversal stiffeners of the steel decks as well as the cross-beams of the steel-and-concrete composite deck were modelled as ribs of the shell members. Considering the actual structural details, all the arch-to-girder joints were considered as rigid. The connections of hangers were approximated by the hinge joints, except for hangers of welded I cross-section of the single track railway bridge $\mathrm{D}$, where the joint was modelled as rigid for out-of-plane bending.

Unlike the previous models, in the "shell" models the main girders and arches, and also their relevant stiffeners and diaphragms, were meshed by the shell elements. The transversal stiffeners or cross beams as well as the frame bracing members and I-shaped hanger members were approximated by $2 \mathrm{D}$ elements too. The truss bracing members and also the hangers made of CHS profiles or rods were modelled by beam elements. Modelling of the other parts of bridge superstructures stayed unchanged. Attention was paid to the correct modelling of joints to approximate real

Basic parameters of bridge superstructures

Table 1

\begin{tabular}{|l|c|c|c|c|c|}
\hline Bridge designation & A & B & C & D & E \\
\hline Arch/bridge span & 62.4 & 66.0 & 81.0 & 84.0 & 124.8 \\
\hline Rise-to-span ratio & $1 / 5.67$ & $1 / 5.50$ & $1 / 7.36$ & $1 / 6.00$ & $1 / 5.67$ \\
\hline Traffic type & two-line railway & one-line railway & two-line road & one-line railway & two-line railway \\
\hline Span-to-width ratio & 5.07 & 5.28 & 6.80 & 13.44 & 9.90 \\
\hline Bridge deck & steel orthotropic & steel orthotropic & steel-concrete & steel orthotropic & steel orthotropic \\
\hline Hangers type and joints & hinged tubes & hinged rods & hinged rods & fixed I-section & hinged tubes \\
\hline Main girder cross-section & box girder & box girder & plate girder & plate girder & box girder \\
\hline Arch cross-section & box section & box section & box section & box section & box section \\
\hline Arch-to-girder joint & rigid & rigid & rigid & rigid & rigid \\
\hline
\end{tabular}




\section{COMMNICOIIONS}

behaviour of structural details. The arch-to-girder connection including corresponding diaphragms in the case of analysed

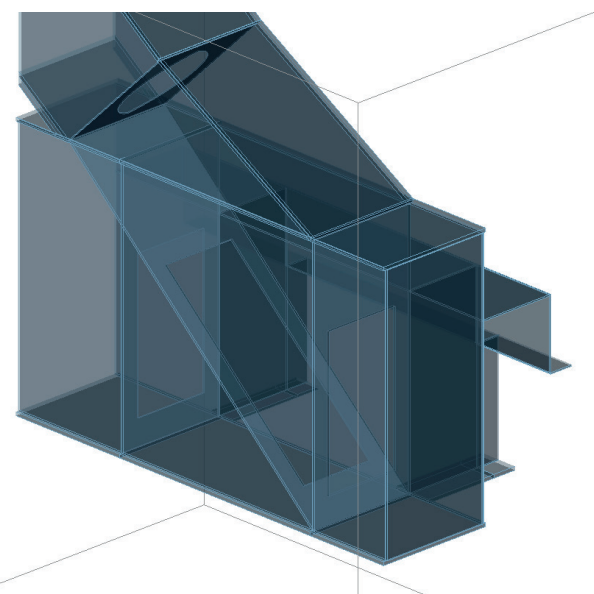

brides $\mathrm{E}$ is illustrated in Fig. 6. Type of mesh elements used in FEM models are summarised in Table 2.

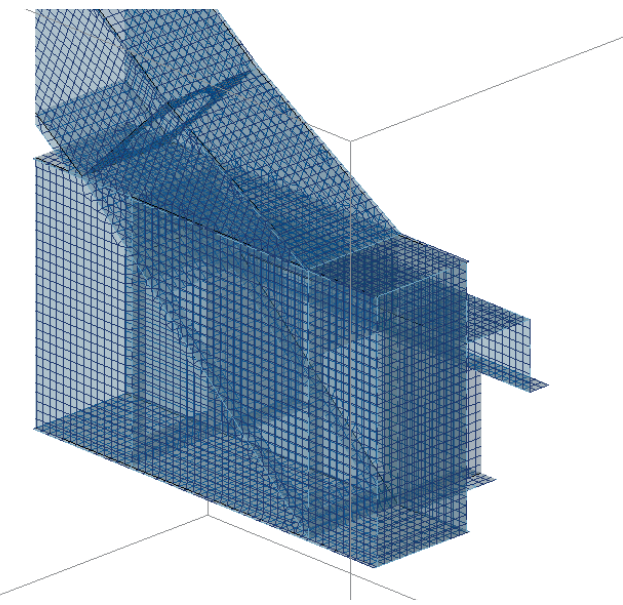

Fig. 6 Detailed view on arch-to-girder connection of the bridge $E$ in shell model alternative

Type of mesh elements used in FEM models

Table 2

\begin{tabular}{|c|c|c|c|c|c|c|}
\hline \multirow{3}{*}{\multicolumn{2}{|c|}{ Use of element type in FEM models }} & \multicolumn{2}{|c|}{ „MEMBER“ models } & \multicolumn{3}{|c|}{ „SHELL“ models } \\
\hline & & \multirow{2}{*}{ Railway bridges } & \multirow{2}{*}{ Road bridge } & \multicolumn{2}{|c|}{ Railway bridges } & \multirow{2}{*}{ Road bridge } \\
\hline & & & & single-line bridge & two-line bridges & \\
\hline \multicolumn{2}{|c|}{ Applied for bridge } & A, B, D, E & $\mathrm{C}$ & D & A, B, E & $\mathrm{C}$ \\
\hline \multirow{4}{*}{ Deck parts } & steel plates & shells & concrete shells & \multicolumn{2}{|c|}{ shells } & concrete shells \\
\hline & $\begin{array}{l}\text { longitudinal } \\
\text { stiffeners }\end{array}$ & beams (ribs) & - & \multicolumn{2}{|c|}{$\begin{array}{l}\text { beams } \\
\text { (ribs) }\end{array}$} & - \\
\hline & transversal stiffeners & beams (ribs) & - & \multicolumn{2}{|c|}{ shells } & - \\
\hline & cross beams & - & beams (ribs) & \multicolumn{2}{|c|}{ - } & shells \\
\hline \multirow{3}{*}{$\begin{array}{l}\text { Main carrying } \\
\text { system }\end{array}$} & main girders & \multicolumn{2}{|c|}{ beams } & \multicolumn{3}{|c|}{ shells (including stiffeners/diaphragms) } \\
\hline & arches & \multicolumn{2}{|c|}{ beams } & \multicolumn{3}{|c|}{ shells (including diaphragms) } \\
\hline & hangers & \multicolumn{2}{|c|}{ beams } & shells & \multicolumn{2}{|c|}{ beams } \\
\hline \multirow{2}{*}{ Bracings } & truss alternatives & \multicolumn{2}{|c|}{ beams } & \multicolumn{3}{|c|}{ beams } \\
\hline & frame alternatives & \multicolumn{2}{|c|}{ beams } & \multicolumn{3}{|c|}{ shells } \\
\hline
\end{tabular}

Calculated values of the factors $\alpha_{\mathrm{cr}}$ for various bracing systems and FEM models

\begin{tabular}{|c|c|c|c|c|c|c|c|c|c|c|}
\hline \multirow{2}{*}{$\begin{array}{l}\text { Bridge } \\
\text { Bracings }\end{array}$} & \multicolumn{2}{|c|}{ A } & \multicolumn{2}{|c|}{ B } & \multicolumn{2}{|c|}{$\mathrm{C}$} & \multicolumn{2}{|c|}{$\mathrm{D}$} & \multicolumn{2}{|c|}{$\mathrm{E}$} \\
\hline & $a_{c r, b^{*}}$ & $a_{c r, s^{*}}$ & $a_{c r, b^{*}}$ & $a_{c r, s^{*}}$ & $a_{c r, b^{*}}$ & $a_{c r, s^{*}}$ & $a_{c r, b^{*}}$ & $\alpha_{c r, s^{*}}$ & $a_{c r, b^{*}}$ & $a_{c r, s^{*}}$ \\
\hline I & 4.57 & 4.65 & 3.83 & 3.93 & 0.71 & 0.76 & 1.53 & 1.51 & 1.76 & 1.83 \\
\hline IIa & 5.06 & 5.34 & 4.25 & 4.21 & 0.80 & 0.87 & 1.90 & 1.70 & 1.94 & 2.02 \\
\hline IIb & 5.25 & 5.36 & 4.43 & 4.39 & 1.29 & 1.06 & 2.36 & 1.88 & 2.85 & 2.32 \\
\hline IIc & 5.46 & 5.52 & 4.48 & 4.50 & 1.81 & 1.21 & 2.75 & 2.01 & 3.43 & 2.48 \\
\hline IIIa & 12.61 & 13.40 & 8.82 & 9.37 & 5.72 & 6.20 & 3.04 & 3.21 & 5.69 & 6.41 \\
\hline IIIb & 13.10 & 12.96 & 9.18 & 9.63 & 5.98 & 6.49 & 3.24 & 3.39 & 5.64 & 6.37 \\
\hline IIIc & 13.34 & 12.31 & 8.80 & 9.15 & 7.13 & 7.32 & 3.39 & 3.53 & 5.71 & 6.37 \\
\hline
\end{tabular}




\subsection{Results of stability analyses}

All the numerical models (beam models as well as shell models) were used for global stability analysis in order to get the first eigenmodes of the loss of structural stability, especially of the arches. These eigenmodes are quantified by the factor $\alpha_{c r}$, by which the design load should be increased to cause the elastic instability in a global mode. The values $\alpha_{c r}$ are shown in Table 3, both for the beam models $\left(\alpha_{c r b}\right)$ and the shell models $\left(\alpha_{c r, s}\right)$.

As could be expected, from the comparison of the amplifier values it can be stated that the frame bracing system is generally less effective than the truss one. In the case of narrow bridges with span-to-width ratio greater than 10.0, the frame system appears to be ineffective $\left(\alpha_{c r}<3.0\right)$. When using the truss bracing, the rhombic system seems to be the most effective. On the contrary, the K-truss system is the least effective, although only small differences were observed. If no bracing is provided, the out-of-plane stability of arches rapidly decreases with increasing span-to-width ratio, especially in the case of small fixation capability of main girder in arch-to-girder joint. In that case, insufficient stiffness of the opened girder cross-section in horizontal bending and torsion results in archends rotation.

The study outlined a significant role of rigidity of the arch-to-girder connection. More precise modelling using shell elements is generally recommended. However, according to the study, application of shell elements does not necessarily lead to more relevant stability data. Especially, in the case of slender cross-section, when many stiffeners are connected to thin plates, they have to be carefully taken into account in the structure model, including their connection, [4]. If local instability is not considered properly, it can result in an increase of the global deformations, e.g. the horizontal deformation of the arches in stability analysis.

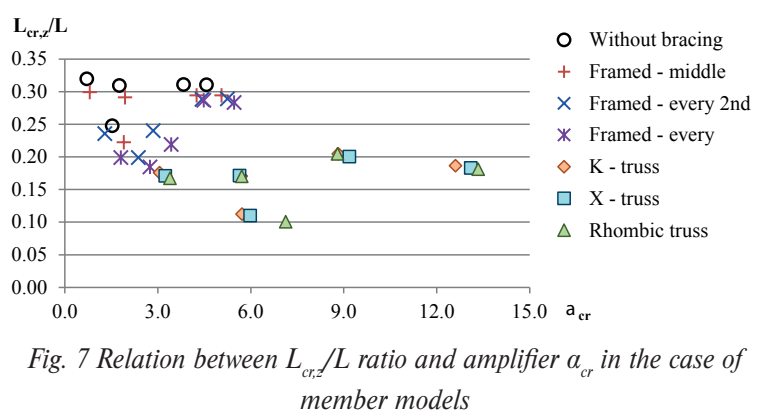

In Fig. 7, the relations between $L_{c r z} / L$ ratio and amplifier $\alpha_{c r}$ in the case of member models is shown. Actually, the out-ofplane buckling lengths of non-braced arches could be considered under $1 / 3$ of the theoretical arch length for all analysed arches. When truss bracing is applied, the out-of-plane buckling length was under $1 / 5$ of the arch length, regardless of the span and the truss type.

\section{Verification of chosen arches}

In some cases, it is very difficult to obtain relevant results without application of geometrically nonlinear elastic analysis with initial imperfections included (GNIA), [5]. Next comparative study was done to recognise if linear analysis is sufficient enough for analysis of abovementioned arches.

The obtained shapes of the elastic critical buckling modes (eigenmodes) from stability analyses were used for assessment of critical sections of the arches by means of second order global analysis. The key problem is to estimate the amplitude of so-called unique global and local imperfection. In the case of common structures, especially when uniaxial bending and in-plane buckling are under consideration, the procedure presented in [6 and 7] can be utilised. When biaxial bending and torsion are present combined with more complicated geometry, a complicated iterative procedure allowing for bending moments about both main axes should be executed [8]. These procedures have been also included in EN 1993-1-1 [9]. However, their application is useful provided that the special software able to solve separately internal forces induced by load cases combination and by the initial imperfections, respectively, is available. The work [10] proposes an alternative generalised approach, which is suitable for use in all cases, even when the common computer program is used. According to this approach, the design value of initial bow imperfection $e_{0, d, g e n}$ can be obtained from the equation

$e_{0, d, \text { gen }}=e_{0, d} \cdot \frac{N_{c r i t} \cdot y_{\max }}{M_{e, \max }}=e_{o, d} \cdot v_{e}$

where $e_{o, d}$ is the design value of initial bow imperfection according to [9], $N_{c r i t}$ is the critical force of the member and $M_{e, \max }$ is the maximum bending moment in the member under investigation when it is bent in the shape of the eigenfunction $y(x)$ with the maximum amplitude $y_{\max } ; v_{e}$ is an amplification factor.

When using the computer program not giving the values $M_{e, \text { max }}$ corresponding to the determined value $y_{\max }$, the amplification factor $v_{e}$ given by equation (1) can be obtained on the basis of affinity between imperfection shape given by the buckling mode and the deflection $\eta(x)$ and moment $M_{z}(x)$ diagrams

$v_{e}=\frac{N_{c r i t} \cdot \eta_{\max }^{I I}}{M_{z, \eta, \max }^{I I}}$

where $\eta_{\max }{ }^{I I}$ and $M_{z, \eta, \max }{ }^{I I}$ are the maximum values of deflection and bending moment, respectively, resulting from the second order analysis using the critical buckling mode with arbitrary maximum amplitude $y_{\max }$. 
For spaced structures, where the critical buckling mode involves bending moments about both main axes, but when the buckling in $y$-y direction is decisive, the formula (2) can be modified as follows

$v_{e}=\frac{N_{c r i t} \cdot \eta_{\max }^{I I}}{M_{z, \eta, \max }^{I I}+M_{y, \eta, \text { max }}^{I I} \cdot W_{y} / W_{z}}$

where $M_{y, \eta, \max }{ }^{I I}$ is the bending moment about $\mathrm{y}-\mathrm{y}$ main axis in the same cross section in which $M_{z, \eta, \max }{ }^{I I}$ occurs and $W_{y}, W_{z}$ are elastic section modules of the cross section.

Utilisation grades of chosen arch members

Table 4

\begin{tabular}{|c|c|c|c|c|c|c|}
\hline Bracing & Analysis & A & B & C & D & E \\
\hline \multirow{2}{*}{ I } & LA & 0.889 & 0.817 & 2,067 & 1,163 & 1.242 \\
\cline { 2 - 7 } & GNIA & 0.834 & 0.801 & - & - & 1,027 \\
\hline \multirow{2}{*}{ IIc } & LA & 0.870 & 0.816 & 1.111 & 0.750 & 0.970 \\
\cline { 2 - 7 } & GNIA & 0.828 & 0.793 & 0.918 & 0.616 & 1,002 \\
\hline \multirow{2}{*}{ IIIc } & LA & 0.762 & 0.726 & 0.767 & 0.678 & 0.852 \\
\cline { 2 - 7 } & GNIA & 0.781 & 0.726 & 0.730 & 0.512 & 0.896 \\
\hline
\end{tabular}

This approach was used in order to verify the chosen arches from the parametric study. The obtained corresponding global eigenmodes of the loss of structural stability were considered as the unique global and local imperfections $\eta_{\text {init }}$ of the arch members. Applying design amplitudes given by equations (1) and (3) to the member models from the presented parametric study, the internal forces in critical sections were obtained using nonlinear second order global analysis. Consequently, the resistance of these critical cross-sections was evaluated and compared to the standard assessment with the equivalent column method according to 6.3.3 in EN 1993-1-1 [9]. The corresponding utilisation efficiency of the arch members obtained by first order analyses and second order analyses, respectively, are presented in Table 4. Only arches with no bracings, with the frame system in every hanger and with rhombic truss bracing, respectively, were chosen for verification (bracing systems designated as I, IIc and IIIc according to Fig. 5). From the comparison it is evident that the lower stability of arch in the higher differences can be observed. The bridge structure $\mathrm{C}$ without bracing (case
I) was found to be unstable, therefore its utilisation grades are not given in the table for this case.

\section{Conclusions}

The paper presents study based on five bow-string arch bridge superstructures. Stability analyses using two types of spatial transformation models by means of FEM software were done. Based on the comparison of applying beam and shell finite elements, respectively, for the mesh of main load-carrying system, it can be stated that application of shell elements does not necessarily lead to more relevant stability data. The rigidity of arch-to-girder connection plays also important role. If excessive local instability occurs in this joint, it can affect the global stability of arches. The study approved an assumption of the higher effectiveness of truss bracing systems comparing to the frame bracings.

Finally, results from geometrically nonlinear analyses using application of initial geometric imperfections into the second order analysis are presented. The amplitudes of elastic critical buckling modes of arches were scaled to be applied as the unique global and local imperfection. The utilisation grades from nonlinear arch verification are compared to the values obtained by the standard assessment by means of the equivalent column method. Results presented above indicate that using of frame bracing systems, in cases of the bridges with rigid connection of box arch to box girder, did not lead into remarkable stability enhancement. Moreover, additional bending moments resulting from framed behaviour of the braced arches caused that the final utilisation of arches stay practically unchanged, in these particular cases

\section{Acknowledgement}

This paper presents results of works supported by the Slovak Research and Development Agency under the contract No. APVV-14-0772 and by the Cultural and Educational Grant Agency KEGA within the project 012ZU-4/2016.

\section{References}

[1] VICAN, J., GOCAL, J., ODROBINAK, J., HLINKA, R.: Design and Stability of Long Span Railway Arch Bridge. Communications - Scientific Letters of the University of Zilina, 4/15, 2013, p. 33-39.

[2] VICAN, J., ODROBINAK, J., GOCAL, J., HLINKA, R.: Design of the Two-Line Railway Bridge with the Longest Span in Slovakia. Proc of $8^{\text {th }}$ intern. conference Bridges in Danube Basin, Timisoara-Belgrade, Romania-Serbia, 2013, Springer Fachmedien: Wiesbaden, 2013, pp. 267-278.

[3] VICAN, J., ODROBINAK, J., GOCAL, J.: Recently Designed Bow-String Railway Bridges in Slovakia. Prof. of $7^{\text {th }}$ Intern. Conference on Arch Bridges ARCH 2013, Trogir-Split, 2013, pp. 427-434. 
[4] FLODR, J., KREJSA, M., MIKOLASEK, D., BROZOVSKY, J., PARENICA, P.: Numerical Modeling of a Thin-Walled Profile with Respect to the Redistribution of Bending Moments. Civil-Comp Proceedings, vol. 108, 2015.

[5] AL ALI, M., TOMKO, M., DEMJAN, I., KVOCAK, V.: Analysis of the Initial Imperfections Effect on the Thin-Walled ColdFormed Compressed Steel Members. Communications - Scientific Letters of the University of Zilina, 4/14, 2012, pp. 83-87.

[6] CHLADNY, E., STUJBEROVA, M.: Frames with Unique Global and Local Imperfection in the Shape of the Elastic Buckling Mode - Part 1, Stahlbau, 82, 2013, Ernst \& Sohn : Berlin, 2013, pp. 609-617.

[7] BALAZ, I., KOLEKOVA, Y.: Structures with UGLI Imperfections. Proc. of $18^{\text {th }}$ Intern. conference Engineering Mechanics 2012, Svratka, pp. 61-86.

[8] CHLADNY, E., STUJBerova, M.: Frames with Unique Global and Local Imperfection in the Shape of the Elastic Buckling Mode - Part 2, Stahlbau, 82, 2013, Ernst \& Sohn : Berlin, 2013, pp. 684-694.

[9] EN 1993-1-1: Eurocode 3: Design of Steel Structures - Part 1-1: General Rules and Rules for Buildings, CEN : Brussels, 2005.

[10] CHLADNY, E., CHLADNA, M.: The Application of Initial Bow Imperfection in the Designs of New Danube Bridges in Slovakia, Proc. of $4^{\text {th }}$ Intern. Conference on Bridges Across the Danube 2001, Bratislava, pp. 179-184. 